7-10-2007

\title{
Mechanical Behavior of Fuel Cell Membranes under Humidity Cycles and Effect of Swelling Anisotropy on the Fatigue Stresses
}

\author{
Ahmet Kusoglu \\ University of Delaware \\ Anette M. Karlsson \\ Cleveland State University, a.karlsson@csuohio.edu \\ Michael H. Santare \\ University of Delaware
}

Bimbent thilegharadditional works at: https://engagedscholarship.csuohio.edu/enme_facpub Erre Fuel Cell Technologies

Part of the Mechanical Engineering Commons

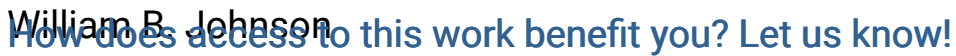

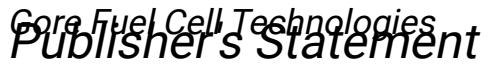

NOTICE: this is the author's version of a work that was accepted for publication in Journal of

Power Sources. Changes resulting from the publishing process, such as peer review, editing, corrections, structural formatting, and other quality control mechanisms may not be reflected in this document. Changes may have been made to this work since it was submitted for publication. A definitive version was subsequently published in Journal of Power Sources, 170, 2, (07-10-2007); 10.1016/j.jpowsour.2007.03.063

\section{Original Citation}

Kusoglu, A., Karlsson, A. M., Santare, M. H., 2007, "Mechanical Behavior of Fuel Cell Membranes Under Humidity Cycles and Effect of Swelling Anisotropy on the Fatigue Stresses," Journal of Power Sources, 170(2), pp. 345-358.

This Article is brought to you for free and open access by the Mechanical Engineering Department at EngagedScholarship@CSU. It has been accepted for inclusion in Mechanical Engineering Faculty Publications by an authorized administrator of EngagedScholarship@CSU. For more information, please contact library.es@csuohio.edu. 


\title{
Mechanical response of fuel cell membranes subjected to a hygro-thermal cycle
}

\author{
Ahmet Kusoglu $^{\text {a }}$, Anette M. Karlsson ${ }^{\mathrm{a}, *}$, Michael H. Santare ${ }^{\mathrm{a}}$, \\ Simon Cleghorn ${ }^{\mathrm{b}}$, William B. Johnson ${ }^{\mathrm{b}}$ \\ a Department of Mechanical Engineering, University of Delaware, DE 19716, United States

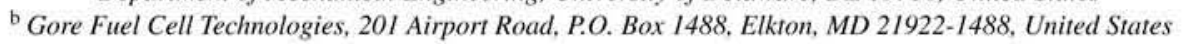

\section{Introduction}

The durability of proton exchange membranes (PEMs) used in fuel cells is a major factor in the operating lifetime of fuel cell systems. Durability is a complicated phenomenon, linked to the chemical and mechanical interactions of the fuel cell components - i.e., electrocatalysts, membranes, gas diffusion layers, and bipolar plates - under severe environmental conditions, such as elevated temperature and low humidity [1-6]. In fuel cell systems, failure may occur in several ways such as chemical degradation of the ionomer membrane or mechanical failure in the PEM that results in gradual reduction of ionic conductivity, increase in the total cell resistance, and the reduction of voltage and loss of output power [1-3,6]. Mechanical damage in the PEM can appear as through-the-thickness flaws or pinholes in the membrane, or delamination between the polymer membrane and gas diffusion layers [3,5-7]. Although the initiation and propagation of flaws and pinholes is not well understood, it

\footnotetext{
* Corresponding author. Tel.: +1 3028316437 ; fax: +1 3028313619. E-mail address: karlsson@udel.edu (A.M. Karlsson).
}

has been suggested that the stresses in the membrane are due to the hygro-thermal cycles even in the absence of electric potential or reactive gases $[1,2,4-8]$. Thus, the purpose of the current work is to investigate the evolution of mechanical stress due to the environmental conditions of a duty cycle.

Work concerning testing, modeling and mechanical characterization of perfluorosulfonic acid (PFSA) membranes, investigating the failure mechanisms in the membranes and how hygro-thermal stresses influence in these failures, is available in the literature [1,2,7-12]. However, failure and degradation mechanisms of the individual components warrant further study. In particular, the non-linear, non-elastic constitutive behavior of the membranes under hygro-thermal cycling and how this affects the lifetime of the fuel cell is not understood.

In a previous study, we investigated the stresses in the PEM under hygro-thermal loading (from the stress free condition at assembly to operating temperature and humidity) $[13,14]$. However, in that study, the polymer was assumed to be linear-elastic. Recent experimental investigations in our laboratory have provided us with more realistic properties of PFSA-membranes [15]. The experiments show that, for relatively small strains, the mechanical response can be approximated with a linear-elastic, 
perfectly plastic constituent behavior. Thus, linear-elastic, perfectly plastic material response with temperature and humidity dependent properties will be incorporated in the numerical simulations. Moreover, we will investigate the response of the membrane during one cycle, simulating a simplified fuel cell duty cycle. After imposing clamping conditions (described below), this cycle consists of loading (from ambient to operating condition), followed by unloading (back to ambient, corresponding to shut-off). We will see that significant residual stresses develop during unloading, introducing in-plane tensile stresses.

In the following, we will outline the assumptions for the material behavior followed by a description of the finite element models and last discuss the results from the simulations.

\section{Theory for isotropic elasto-plasticity}

Here, we outline the approach used to incorporate hygrothermal effects into a finite element simulation, including isotropic plasticity. This is an extension of previous work $[13,14]$, where only the elastic behavior of the membrane was considered. An uncoupled theory is assumed, for which the additional temperature changes brought by the strain are neglected. We assume that the total strain tensor, $\varepsilon_{i j}$, is the sum

$\varepsilon_{i j}=\varepsilon_{i j}^{\mathrm{e}}+\varepsilon_{i j}^{\mathrm{pl}}+\varepsilon_{i j}^{T}+\varepsilon_{i j}^{\mathrm{S}}$,

where $\varepsilon_{i j}^{\mathrm{e}}$ is the elastic strain component, $\varepsilon_{i j}^{\mathrm{pl}}$ the plastic strain component and $\varepsilon_{i j}^{T}$ and $\varepsilon_{i j}^{\mathrm{S}}$ are the temperature and swelling induced strains, respectively. Let $T_{0}$ be the reference temperature and $T$ is the current temperature. The thermal strains resulting from a change in temperature of an unconstrained isotropic volume are given by

$\varepsilon_{i j}^{T}=\alpha\left(T-T_{0}\right) \delta_{i j} \quad$ with $\quad \delta_{i j}=\left\{\begin{array}{ll}1 & \text { if } i=j \\ 0 & \text { if } i \neq j\end{array}\right.$,

where $\alpha$ is the linear coefficient of thermal expansion, having units of $\mathrm{K}^{-1}$, and $\delta_{i j}$ is the Kronecker delta. Similarly, the swelling strains caused by moisture uptake are given by

$\varepsilon_{i j}^{\mathrm{S}}=\beta_{i j}(T, H)\left(C-C_{0}\right)$,

where $C$ is the relative humidity and $C_{0}$ is the reference value for $C$. Moreover, $\beta_{i j}(T, H)$ is the temperature and humidity dependent swelling-expansion coefficient tensor due to moisture absorption. For an isotropic material, $\beta_{i j}(T, H)=\beta(T, H) \delta_{i j}$. The swelling-expansion coefficient is usually defined as the relative change in length per $1 \%$ water weight gain. In the current application, the relative humidity rather than the water gain is assumed to be known, thus here the swelling-expansion coefficient is defined as the relative change in length per $1 \%$ relative humidity change. Consequently, the units of $\beta$ are $1 \% \mathrm{RH}^{-1}$.

Assuming linear response within the elastic region, the isotropic Hooke's law is used to determine the stress tensor, $\sigma_{i j}$ :

$\sigma_{i j}=\frac{E}{(1+v)(1-2 v)}\left[v \delta_{i j} \varepsilon_{k k}^{\mathrm{e}}+(1-2 v) \varepsilon_{i j}^{\mathrm{e}}\right]$, where $\varepsilon_{k k}^{\mathrm{e}}=\varepsilon_{11}^{\mathrm{e}}+\varepsilon_{22}^{\mathrm{e}}+\varepsilon_{33}^{\mathrm{e}}, E$ is Young's modulus and $v$ is Poisson's ratio. Generalized plane strain is assumed in the simulations:

$\varepsilon_{13}=\varepsilon_{31}=\varepsilon_{23}=\varepsilon_{32}=0$ and $\varepsilon_{33}=$ constant.

For the inelastic response, incompressible plastic deformation is assumed, where rate-independent plastic flow, according to the von Mises yield function is used (J2-flow theory) [16]:

$f\left(\sigma_{i j}\right)=\sqrt{\frac{3}{2} S_{i j} S_{i j}}-\sigma_{0}$,

where $\sigma_{i j}$ is the components of the (true) stress tensor and $\sigma_{0}$ is the yield strength. For simplicity, we will assume that the material is perfectly plastic, thus the yield strength does not depend on the plastic strain but only temperature and humidity. Therefore, the yield strength can be rewritten as

$\sigma_{0}=\sigma_{0}(T, H)$.

Furthermore, in Eq. (6) $S_{i j}$ are the components of the deviatoric stress tensor is defined by

$S_{i j}=\sigma_{i j}-\frac{1}{3} \sigma_{k k} \delta_{i j}$.

According to the von Mises yield criterion, yield occurs when

$f\left(\sigma_{i j}\right)=0$.

For $f\left(\sigma_{i j}\right)<0$, the material deforms elastically.

The Mises flow theory predicts that the plastic strain increment tensor must be proportional to the deviatoric stress tensor, thus

$\mathrm{d} \varepsilon_{i j}^{\mathrm{pl}}=S_{i j} \mathrm{~d} \lambda$,

where $\mathrm{d} \lambda$ is a scalar proportionality factor.

\section{Material properties}

The material properties for the graphite plates are set to those of commercial graphite and for the carbon paper from TORAY ${ }^{\circledR}$ TGP-H-030 [18]. It is assumed that these materials have linearelastic behavior and do not swell in response to moisture.

Linear-elastic, perfectly plastic constitutive behavior with temperature and humidity dependent material properties is assumed for the membrane. Young's modulus and yield strength of the membrane are defined for four temperature and relative humidity values based on our experimental data for $\mathrm{Nafion}^{\circledR} 112^{1}$ [15]. The tensile tests of the Nafion ${ }^{\circledR}$ films were conducted in an environmental chamber within a temperature range from 25 to $85^{\circ} \mathrm{C}$, and a relative humidity range from 30 to $90 \% \mathrm{RH}$ to obtain true stress-true strain curves at each temperature-humidity point [15], then Young's modulus and yield strength are calculated at these points. Even though a slight anisotropy in the material properties was observed experimentally [15], in this study we assume for simplicity that the material properties are

\footnotetext{
${ }^{1}$ Nafion ${ }^{\circledR}$ is a registered trademark of E.I. DuPont De Nemours \& Co.
} 
Table 1

Material properties used in finite element analysis [17,18]

\begin{tabular}{|c|c|c|c|c|c|c|c|}
\hline Component (material) & $k\left(\mathrm{~W} \mathrm{~m}^{-1} \mathrm{~K}^{-1}\right)$ & $\rho\left(\mathrm{kg} \mathrm{m}^{-3}\right)$ & $E(\mathrm{MPa})$ & $v$ & $\alpha\left(10^{-6} \mathrm{~K}^{-1}\right)$ & $\beta\left(\mathrm{mm} \mathrm{mm}^{-1} \% \mathrm{RH}^{-1}\right)$ & $C_{p}\left(\mathrm{~J} \mathrm{~kg}^{-1} \mathrm{~K}^{-1}\right)$ \\
\hline Bipolar plates (graphite) & 95 & 1800 & 10000 & 0.25 & 5 & Neglected & 750 \\
\hline GDE (carbon paper) & 0.3 & 400 & 10000 & 0.25 & -0.8 & Neglected & 500 \\
\hline Membrane (Nafion ${ }^{\circledR} 112$ ) & 0.259 & 2000 & Table 2 & 0.25 & 123 & $\beta(T, H)$ (from Fig. 1) & 1050 \\
\hline
\end{tabular}

isotropic. Additional physical properties for the membrane were adopted from the DuPont Nafion ${ }^{\circledR}$ PFSA Membranes N-112 Data Sheet [18]. The material properties for the membrane and other components used in this study are shown in Tables 1-3 and Fig. 1.

Table 2

Young's modulus at various temperatures and humidities for Nafion ${ }^{\circledR} 112$ [15]

\begin{tabular}{llcrr}
\hline Young's modulus $^{\mathrm{a}}$ (MPa) & \multicolumn{5}{l}{ Relative humidity $(\%)$} \\
\cline { 2 - 5 } & 30 & 50 & 70 & 90 \\
\hline$T=25^{\circ} \mathrm{C}$ & 197 & 192 & 132 & 121 \\
$T=45^{\circ} \mathrm{C}$ & 161 & 137 & 103 & 70 \\
$T=65^{\circ} \mathrm{C}$ & 148 & 117 & 92 & 63 \\
$T=85^{\circ} \mathrm{C}$ & 121 & 85 & 59 & 46 \\
\hline
\end{tabular}

${ }^{a}$ Linear interpolation between given data points is used during the loading and unloading.

Table 3

Yield strength at various temperatures and humidities for Nafion ${ }^{\circledR} 112[15]$

\begin{tabular}{lllll}
\hline Yield stress $^{\mathrm{a}}(\mathrm{MPa})$ & \multicolumn{4}{l}{ Relative humidity $(\%)$} \\
\cline { 2 - 5 } & 30 & 50 & 70 & 90 \\
\hline$T=25^{\circ} \mathrm{C}$ & 6.60 & 6.14 & 5.59 & 4.14 \\
$T=45^{\circ} \mathrm{C}$ & 6.51 & 5.21 & 4.58 & 3.44 \\
$T=65^{\circ} \mathrm{C}$ & 5.65 & 5.00 & 4.16 & 3.07 \\
$T=85^{\circ} \mathrm{C}$ & 4.20 & 3.32 & 2.97 & 2.29
\end{tabular}

a Linear interpolation between given data points is used during the loading and unloading.

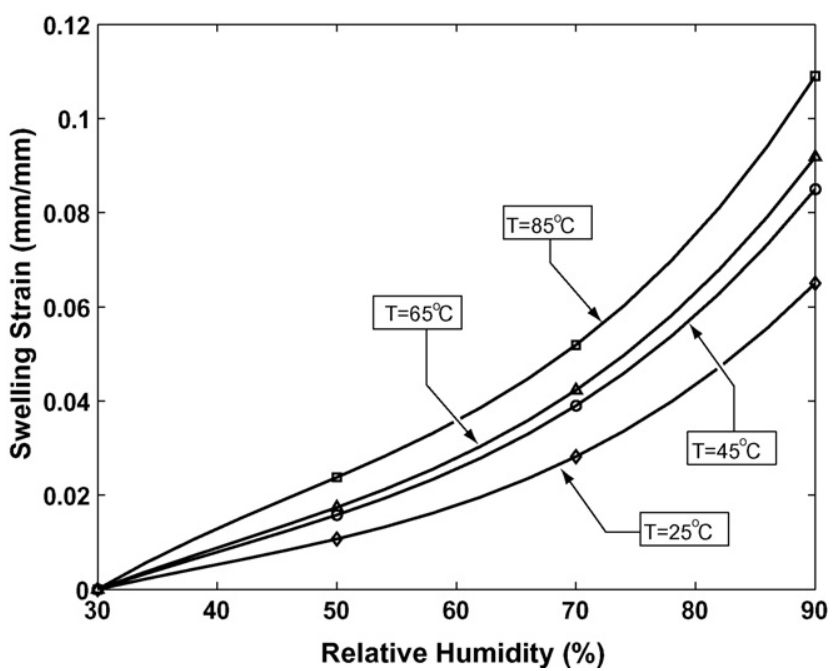

Fig. 1. Experimental data for dimensional change due to the swelling expansion and the polynomial curve fit to the experimental data as a function of humidity and temperature plotted for four constant temperatures for Nafion ${ }^{\circledR} 112$ [15].

\section{Finite element model}

\subsection{Assumptions}

A two-dimensional finite element model was developed, assuming generalized plane strain conditions, including the following simplifying assumptions:

(1) Simplified temperature and humidity profiles with no heat generation were assumed.

(2) The electrodes are assumed to be integrated into the gas diffusion layer (GDL) to form a GDE instead of considering this as a separate layer.

(3) For the GDE and the bipolar plate, the deformation is assumed elastic, whereas the membrane is allowed to deform plastically.

(4) All material properties are assumed to be isotropic including the expansions due to the thermal load and moisture uptake.

(5) One hygro-thermal load cycle (roughly corresponding to a fuel cell duty cycle) is applied which is a simultaneous loading due to the moisture uptake and thermal expansion followed by an unloading to the initial state.

The model used in the current investigation is an extension of a model developed in previous studies $[13,14]$. In the current work, we incorporate temperature and humidity dependent properties of the PEM, as well as including plasticity and investigating the response to one simplified duty cycle.

\subsection{Geometry}

A schematic drawing of a PEMFC unit cell used in the FE model is shown in Fig. 2.

Two geometries with respect to the gas channels are modeled. The gas channels in the graphite plates are used for transport of the hydrogen to the anode side of the membrane electrode assembly (MEA) and air to the cathode, while water vapor is carried away. In most cases, the channels on either side of the MEA are aligned with each other. However, in other cases they are not aligned, for example due to manufacturing flaws. Thus, two graphite plate alignments are selected to study the effects of the geometry of the gas flow channels: (1) aligned and (2) alternating. In both cases, the thickness of plates is $11 \mathrm{~mm}$, and the depth and the width of grooves in the plate are $1 \mathrm{~mm}$.

Furthermore, two clamping methods are investigated: (1) fixed force, corresponding to a case where the fuel cell stack is equipped with springs to control the claming force and (2) fixed displacement where the graphite plates are clamped preventing 


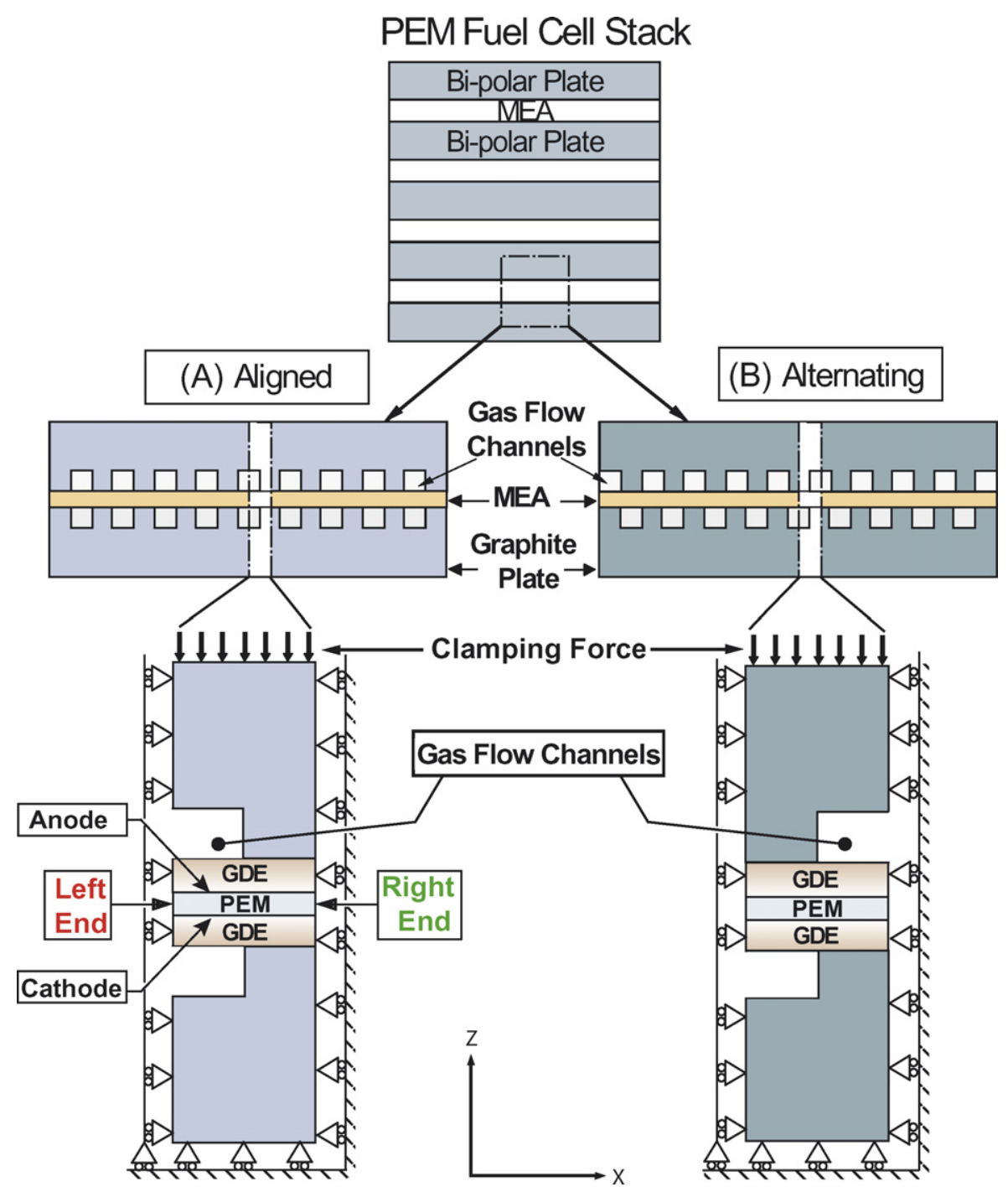

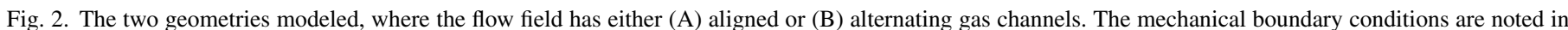

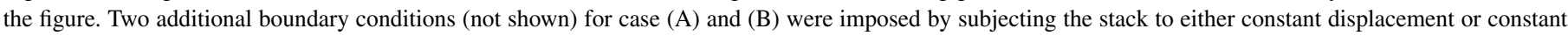
force clamping at the top.

any overall deformation in the thickness direction. In the former case, a constant pressure $(1 \mathrm{MPa})$ is applied on the surface of upper graphite plate. In the latter case, the applied displacement is calculated by applying a $1 \mathrm{MPa}$ load to an otherwise unloaded model, and the resulting displacement at the upper boundary is fixed throughout the analysis.

The membrane thickness is $50 \mu \mathrm{m}$ (corresponding to the thickness of Nafion ${ }^{\circledR} 112$ ). As mentioned previously, the catalyst layer is included in the gas diffusion layer, forming a gas diffusion electrode (GDE) with a thickness of $100 \mu \mathrm{m}$.

The commercial software, ABAQUS 6.4 [19] is used to conduct the simulations. To simulate a unit cell, continuous boundary conditions are applied on the model (Fig. 2). These are manifested as $u_{z}=0$ applied on the bottom, and $u_{x}=0$ on the right side (Fig. 2). A linear constraint $A_{1} u_{x}^{N_{1}}+A_{2} u_{x}^{N_{2}}=0$ is applied along the left edges of the unit cell. Here, $A_{1}=1$ and $A_{2}=-1, N_{1}$ is the node at the bottom left and $N_{2}$ are the remaining nodes on the left side. This condition constrains the right hand side to displace uniformly. Four-node generalized plane strain temperature-displacement coupled elements (CPEG4T) are used in the FE analysis.

\subsection{Simulating eigenstrain: swelling and thermal expansion}

The total strain in the membrane due to the moisture and temperature change is calculated from the coefficients of swelling and thermal expansion. To achieve this in the simulations, the user subroutine UEXPAN [19] is used. A constant thermal expansion coefficient, $\alpha$ (Table 1), and a swelling-expansion coefficient, $\beta(T, H)$, expressed as a polynomial function of humidity and temperature are used in this subroutine to define the expansion of the membrane from initial state $(35 \% \mathrm{RH}$ and $\left.20^{\circ} \mathrm{C}\right)$ to the hydrated state $\left(100 \% \mathrm{RH}\right.$ and $\left.85^{\circ} \mathrm{C}\right)$. UEXPAN calculates an eigenstrain based on the state of the defined field variables humidity and temperature, relative to the initial state 
Table 4

Constants of the swelling strain polynomial $\left(C_{j i}\right)$ as defined in Eq. (11)

\begin{tabular}{rrrrr}
\hline & \multicolumn{1}{c}{$i=1$} & \multicolumn{1}{c}{$i=2$} & \multicolumn{1}{l}{$i=4$} \\
\hline$j=1$ & $3.0816 \mathrm{E}-12$ & $-4.4727 \mathrm{E}-10$ & $2.2696 \mathrm{E}-08$ & $-7.5602 \mathrm{E}-08$ \\
$j=2$ & $-5.3516 \mathrm{E}-10$ & $7.6152 \mathrm{E}-08$ & $-3.7261 \mathrm{E}-06$ & $2.3356 \mathrm{E}-05$ \\
$j=3$ & $3.6359 \mathrm{E}-08$ & $-5.2865 \mathrm{E}-06$ & $2.6400 \mathrm{E}-04$ & $-2.1601 \mathrm{E}-03$ \\
$j=4$ & $-6.9232 \mathrm{E}-07$ & $1.0213 \mathrm{E}-04$ & $-5.1794 \mathrm{E}-03$ & $4.5824 \mathrm{E}-02$ \\
\hline
\end{tabular}

(recall that the materials are assumed to have isotropic thermal and swelling-expansion behavior that is uncoupled).

The coefficient of swelling expansion, $\beta(T, H)$, is derived from the swelling strain polynomial function which is obtained by curve fitting to the experimental data of swelling strains (Fig. 1). The swelling strain polynomial is defined as

$\varepsilon^{\mathrm{S}}(T, H)=\sum_{i, j=1}^{4} C_{j i} T^{4-i} \mathrm{RH}^{4-j}$,

where $T$ and $H$ are the temperature $\left({ }^{\circ} \mathrm{C}\right)$ and relative humidity (\%), respectively. The constants of the polynomial $C_{j i}$ are given in Table 4.

\subsection{Simulation of a fuel cell duty cycle}

A fuel cell duty cycle is simulated by first defining "initial conditions," followed by conducting three (ABAQUS) steps:

The initial conditions corresponding to zero stress-state are defined; all components of the cell stack are set to room temperature $20^{\circ} \mathrm{C}$, and relative humidity $35 \%$ (corresponding to the assembly conditions). Since we do not have experimental data for temperatures below $25^{\circ} \mathrm{C}$ and relative humidities below $35 \%$, the material properties used below these values are assumed to be constant.

- Step 1: Impose the clamping condition (fixed force or fixed displacement as described above).

- Step 2: Hygro-thermal loading is applied by linearly increasing the relative humidity of the membrane up to $100 \%$, and defining an estimated temperature profile as follows: cathode/GDE and anode/GDE interface temperatures are at 86 and $85^{\circ} \mathrm{C}$, respectively, and the bipolar plate is assumed to have a constant temperature at its mid-plane, $80^{\circ} \mathrm{C}$ which is the cell operating temperature. These values are reasonable for a fuel cell operating at $80^{\circ} \mathrm{C}$ under typical conditions [15]. During the cycle, the internal temperature distribution profile in the membrane was calculated from these boundary conditions. The resulting temperature profile is shown in Fig. 3.

- Step 3: Unloading is achieved by linearly decreasing the relative humidity and temperature to the initial relative humidity and temperature values, but leaving the clamping conditions imposed.

Thus, this simplified duty cycle corresponds to taking the cell from start-up to hydrated operation and then back to shut-down, assuming the cell is left to dryout during shut-down.
Temperature $\left({ }^{\circ} \mathrm{C}\right)$

80

8586

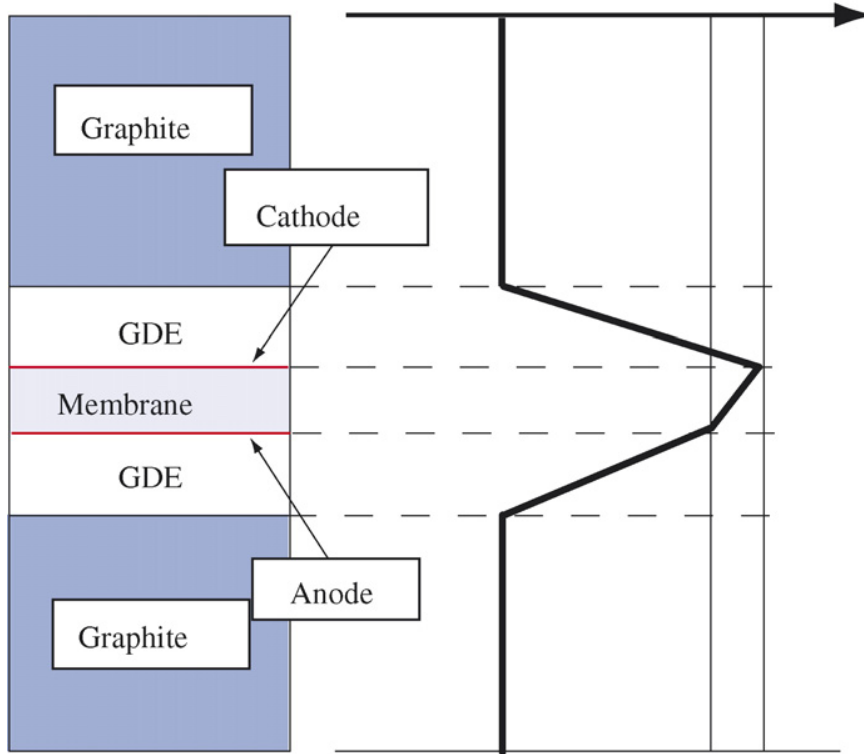

Fig. 3. The temperature profile for the unit fuel cell, assuming a constant anode/GDE temperature of $85^{\circ} \mathrm{C}$ and cathode/GDE temperature of $86^{\circ} \mathrm{C}$ $[13,14]$.

\section{Results and discussion}

\subsection{Stress and deformation history of the selected points}

First, we will investigate the stress histories at two selected points of the membrane for each case, throughout the cycle. The "left end" and "right end," as marked in Fig. 2, are tracked to elucidate the evolution of the stresses through the loading-unloading sequence. The effective stresses according to von Mises, "Mises stresses," given by

$\sigma_{\mathrm{M}}=\overline{\frac{3}{2} S_{i j} S_{i j}}$

are a useful measurement of the effective stress. When $\sigma_{M} \geq \sigma_{0}$, yielding occurs, according to Eq. (6).

The Mises stresses that develop during the cycle are plotted together with the yield strength in tension and compression to determine when the yield strength is reached and the plastic deformation begins (Fig. 4). Yield strength for each temperature and humidity combination reached, was determined using a linear interpolation method between the values of the yield strength obtained at 16 temperature-humidity points from the experiments [15]. Although the Mises stress is by definition always positive, we have associated a sign of the Mises stress with the trend of the major stress component (in-plane stress) for comparison. This way a general trend can be determined revealing overall compressive or tensile behavior. The history plots for the in-plane stresses are shown in Fig. 5. From these results, it can be seen that the Mises stress strongly depends on the in-plane stress component. 

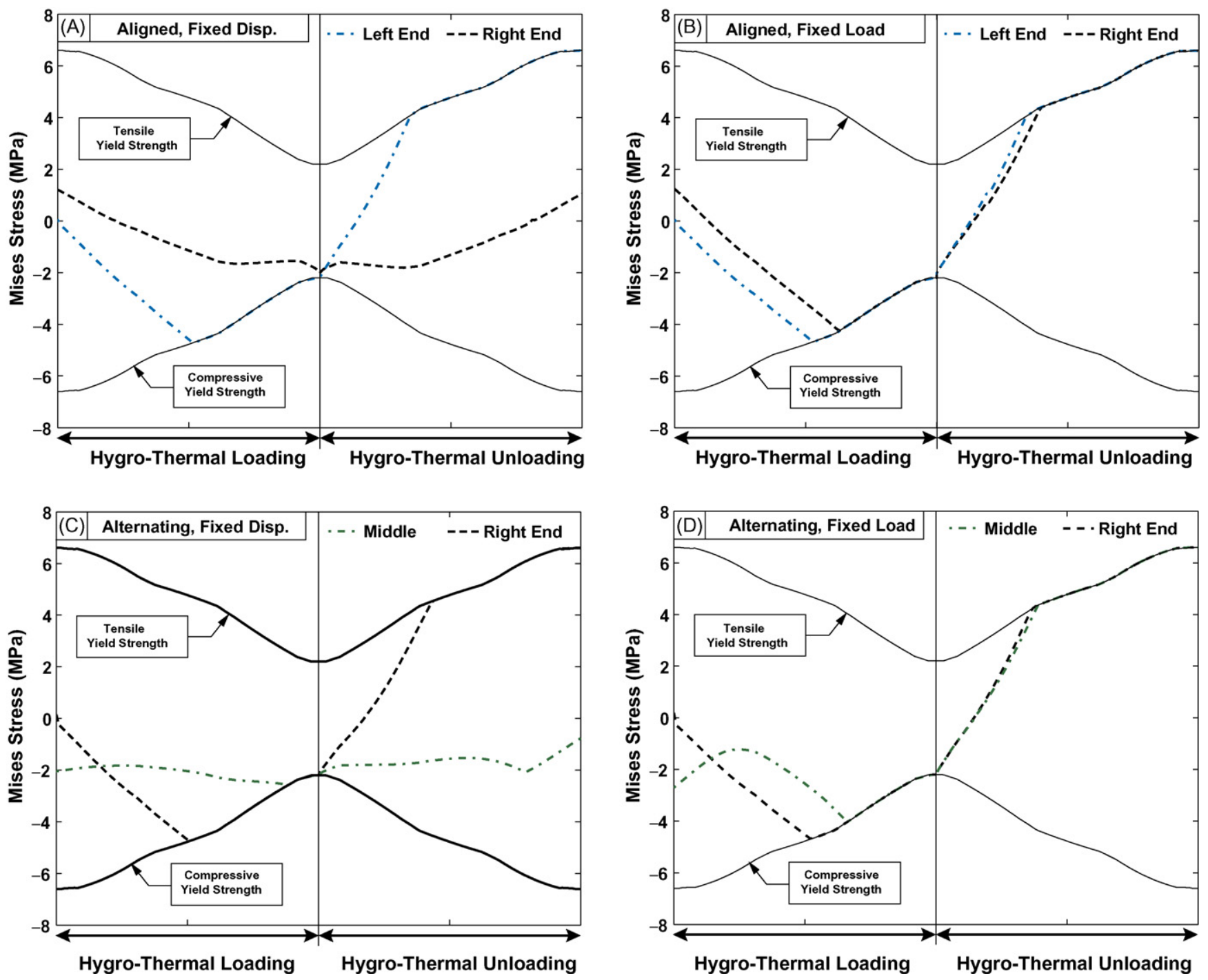

Fig. 4. The evolution of the Mises stress during one simulated fuel cell duty cycle plotted with the yield strength of the membrane for the selected points for (A) aligned, fixed displacement; (B) aligned, fixed force; (C) alternating, fixed displacement and (D) alternating, fixed force. The apparent sign of the Mises stress is obtained by following the trend of the in-plane stress. The cycle is characterized with hygro-thermal loading from initial state, $20^{\circ} \mathrm{C}, 35 \% \mathrm{RH}$, to maximum load $85^{\circ} \mathrm{C}, 100 \% \mathrm{RH}$, and for unloading from maximum load back to initial state.

Initially the membrane is pre-stressed due to the applied clamping as explained previously. During the hygro-thermal loading, the in-plane stress and the Mises stress increase in compression to eventually reach yielding (Fig. 4). After initial yielding occurs the internal forces are redistributed to accommodate additional loading. Upon unloading, the compressive stresses decrease, eventually leading to tensile stresses (Fig. 4). Thus, due to the yielding at elevated temperatures, the load cycle imposes a residual, tensile stress in the membrane.

\subsection{Stress distribution along the membrane}

With the evolution of the stresses (for selected points) throughout the cycle established, we will next investigate the overall stress distribution at maximum temperature and after unloading. Fig. 6 shows the stress distributions in the membrane for the alternating - fixed force case at maximum hygro-thermal load and after unloading. At maximum load $\left(85^{\circ} \mathrm{C}, 100 \% \mathrm{RH}\right)$, the membrane is in overall yielding (Fig. 6A). As discussed in the previous sub-section, the yielding results in a redistribution of the internal forces and stresses. Consequently, tensile in-plane stresses are achieved upon unloading $\left(20^{\circ} \mathrm{C}, 35 \%\right.$ RH) (Fig. 6B). We note that if yielding did not occur during loading, the stresses after unloading would be identical to the initial stresses (stresses due to the clamping - fixed force or fixed displacement - only).

Fig. 7 shows the stress distribution along the top edge of the membrane, after loading and unloading for the alternating - fixed displacement case. Considering the in-plane stress and the Mises stress distribution for the alternating case (Figs. 8B and 9B) suggest that the Mises stress is dominated by the in-plane stress during the deformation. The out-of-plane stress is always smaller than the in-plane stress, although they are at the same order of magnitude in some limited situations. In the confined regions of the membrane (i.e. midpoint of the mem- 

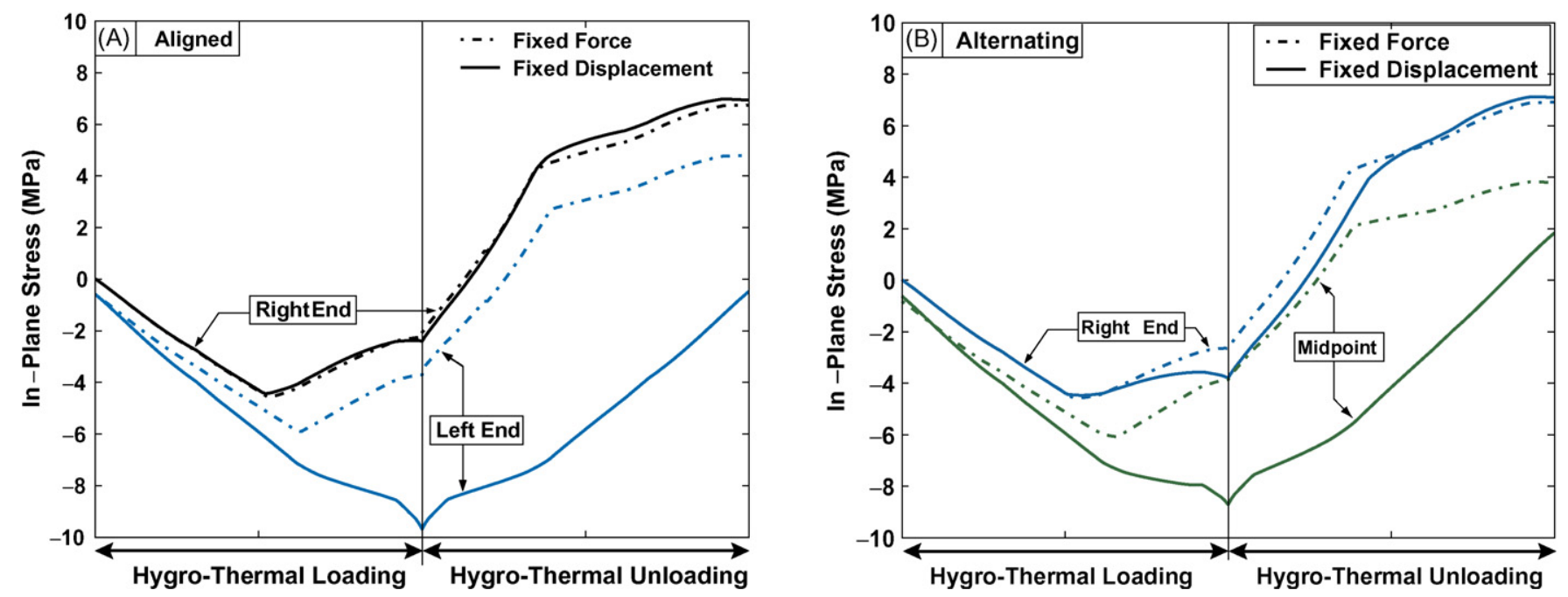

Fig. 5. The evolution of the in-plane stress during one fuel cell duty cycle plotted for the selected points for (A) aligned and (B) alternating case for each clamping method. The cycle is characterized with hygro-thermal loading from initial state, $20^{\circ} \mathrm{C}, 35 \% \mathrm{RH}$, to maximum load $85^{\circ} \mathrm{C}, 100 \% \mathrm{RH}$, and for unloading from maximum load back to initial state.
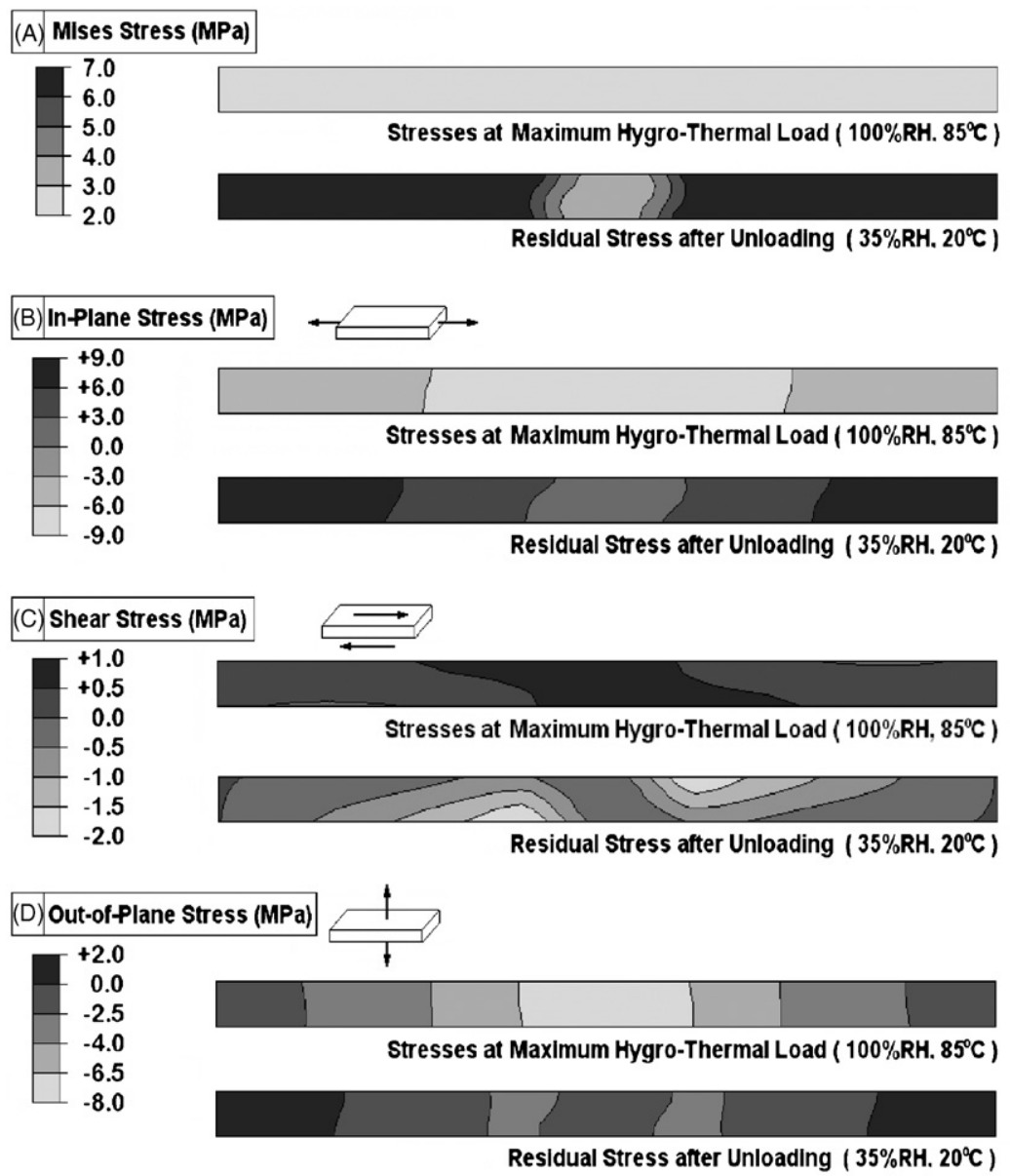

"Left End"

"Right End"

Fig. 6. The contour plots of the membrane for alternating—fixed displacement, at maximum hygro-thermal load and after unloading ("residual stress"), (A) Mises stress, (B) in-plane stress, (C) in-plane shear stress and (D) out-of-plane stress. 


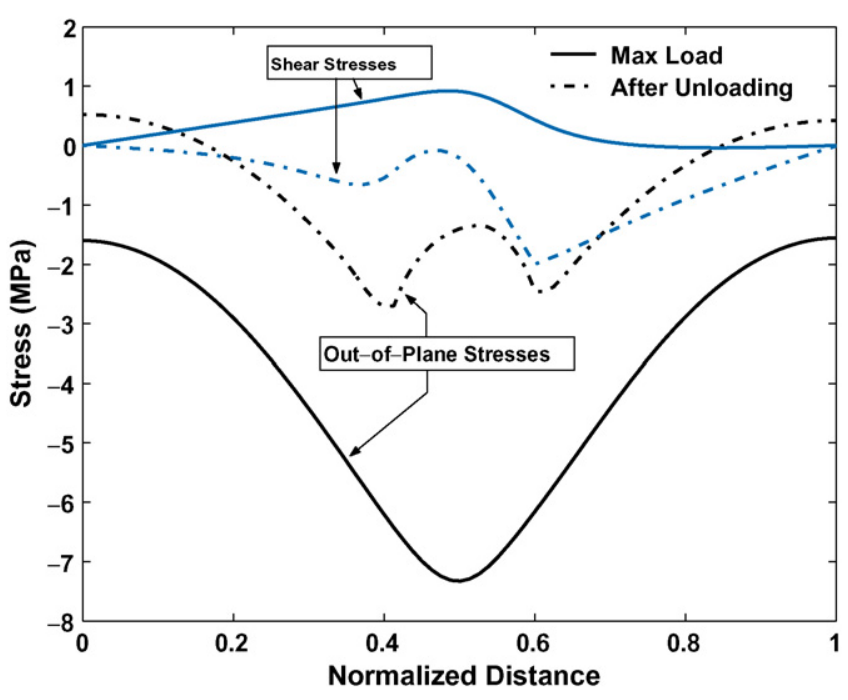

Fig. 7. Shear stress and the out-of-plane stress at maximum hygro-thermal load and after unloading for alternating, fixed displacement as a function of location along the membrane.
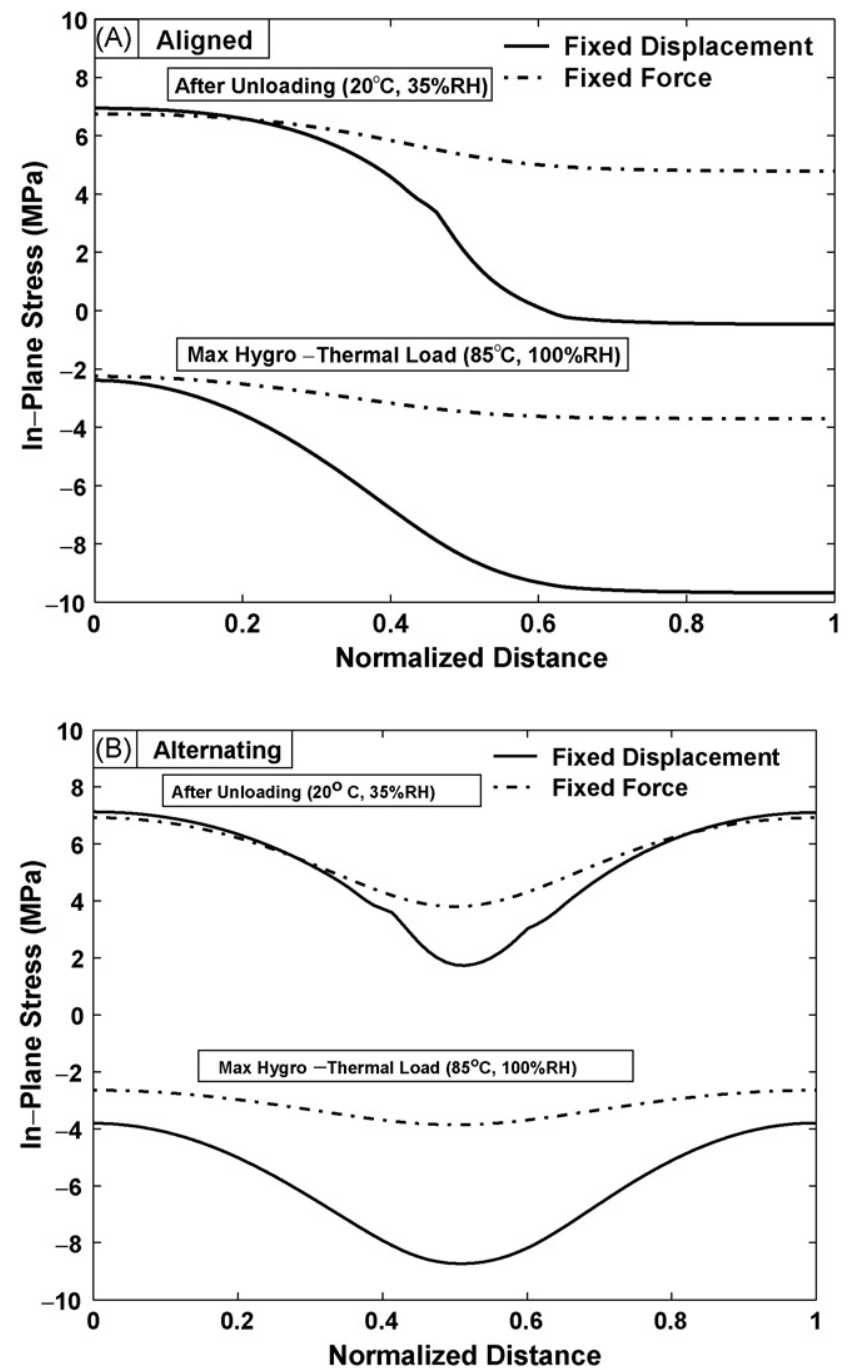

Fig. 8. In-plane stress at maximum hygro-thermal load $\left(85^{\circ} \mathrm{C}, 100 \% \mathrm{RH}\right)$ and after unloading $\left(20^{\circ} \mathrm{C}, 35 \% \mathrm{RH}\right)$ for (A) aligned and (B) alternating cases, for two clamping methods as a function of location along the membrane.
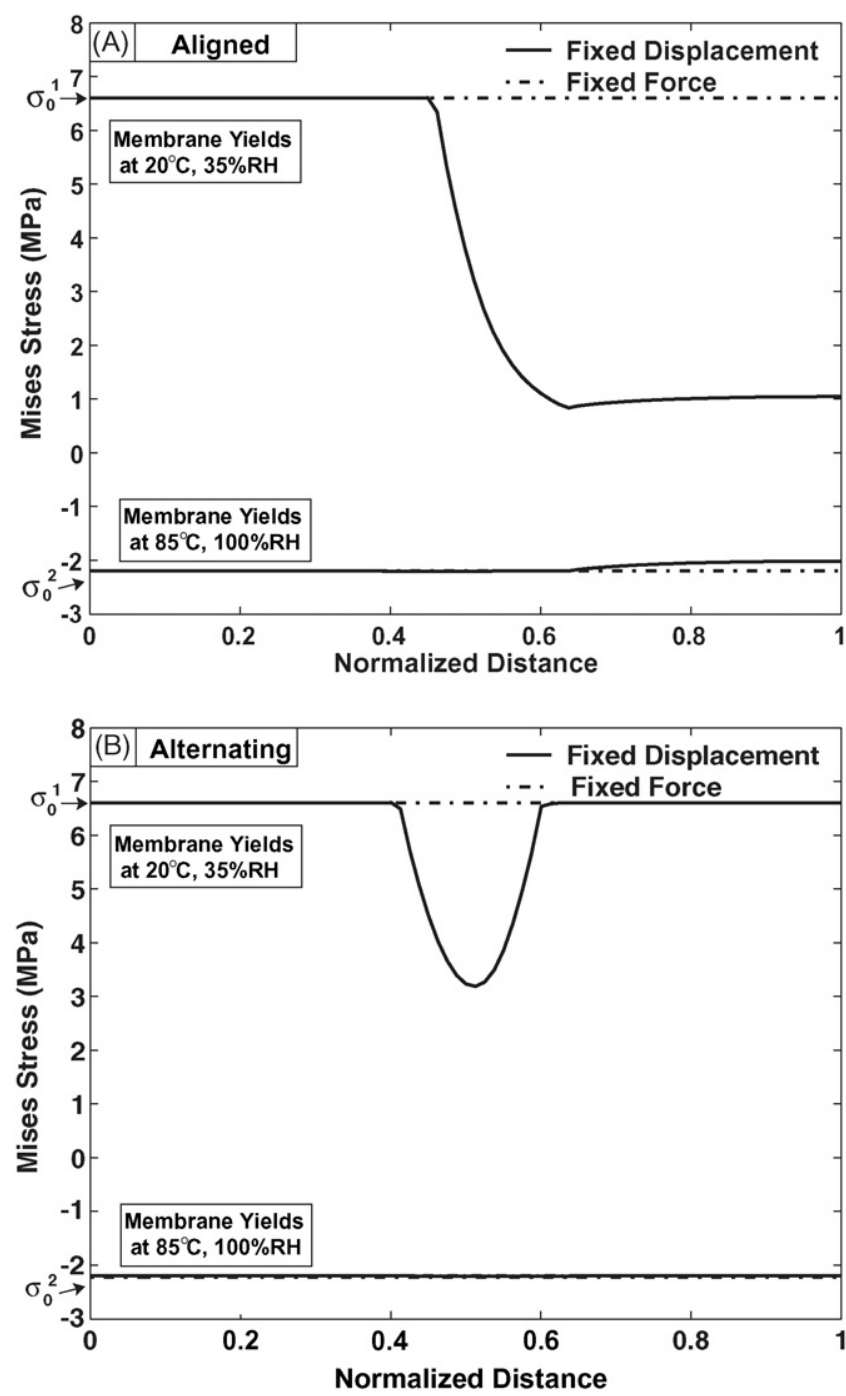

Fig. 9. Mises stress at maximum hygro-thermal load $\left(85^{\circ} \mathrm{C}, 100 \% \mathrm{RH}\right)$ and after unloading $\left(20^{\circ} \mathrm{C}, 35 \% \mathrm{RH}\right)$ for (A) aligned and (B) alternating cases and, two different clamping methods as a function of location along the membrane. $\sigma_{0}^{1}$ and $\sigma_{0}^{2}$ denote the yield strengths at $20^{\circ} \mathrm{C}, 35 \% \mathrm{RH}$ and at $85^{\circ} \mathrm{C}, 100 \% \mathrm{RH}$, respectively.

brane in Fig. 7), the out-of-plane stress becomes large enough to have the same contribution as the in-plane stress. This is particularly true in the case of fixed displacements. Shear stresses are small and may be neglected for all other cases. The in-plane and Mises stress distribution for the aligned case are shown in Figs. 8A and 9A for comparison.

The plastically deformed regions can be visualized from the Mises stress distribution (Fig. 9A and B). The regions of the membrane that deform plastically after hygro-thermal loading depend on the clamping method and the alignment of the model. For the aligned-fixed displacement case, the right part of the membrane (Fig. 9A) remained elastic during the deformation. In this case, the right part of the membrane is constrained from all sides which leads to large hydrostatic compression component. ${ }^{2}$

\footnotetext{
${ }^{2}$ According to Mises yield criterion, Eq. (9), hydrostatic pressure does not influence yielding.
} 


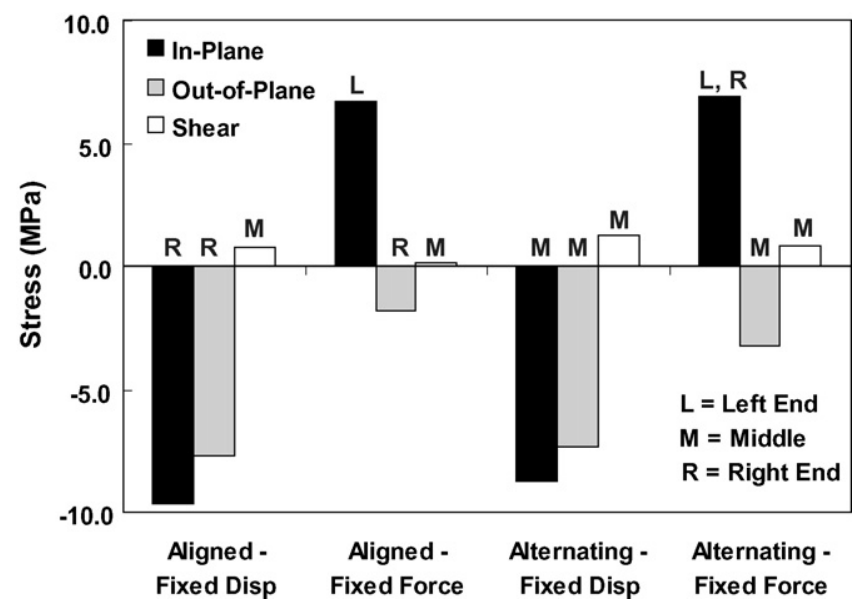

Fig. 10. Maximum values of the stress components; in-plane, out-of-plane and shear, respectively, induced in the membrane by the hygro-thermal loading are shown for each alignment and clamping method. Letters on the columns indicate the location of the stress in the membrane, where L corresponds to the left end; $\mathrm{M}$ to the midpoint, and $\mathrm{R}$ to the right end.

For the aligned case, the right end of the membrane is constrained between the GDE and bipolar plates, and the left end of the membrane can expand freely due to the thermal and swelling strains, which eventually leads to different deformation behavior and stress values. For the alternating case, due to the symmetry with respect to midpoint of the membrane, the left and right ends have the same stresses and the middle point has the maximum stresses.

\subsection{Maximum stresses in the membrane}

Finally, we will consider the magnitude of the maximum stresses. The maximum stresses generated in the membrane during the hygro-thermal cycle are summarized in Fig. 10. The location of the maximum stress is indicated and classified as belonging to the left side (L), the middle (M), or the right side $(\mathrm{R})$ of the membrane. The locations are determined from Figs. 7 and 8 according to the following:

(i) As indicated in Fig. 10, the in-plane stresses are always higher than the out-of-plane stresses. However, for fixed displacement, the out-of-plane stresses are close to the inplane stresses and their maxima are at the same points: at the right end for the aligned case, and at the midpoint for the alternating case.

(ii) For the fixed force case, the maximum in-plane stresses are tensile, whereas the out-of-plane stresses are smaller and compressive. Since the fixed force clamping allows expansion of the unit cell, the membrane is not constrained along the grooves and tensile stresses develop upon unloading. Therefore the maximum in-plane stresses occur at the left end for the aligned case, and at the left and right end for the alternating case (Fig. 8). The maximum of the out-of-plane stresses are at the right end for the aligned case, and at the midpoint for the alternating case.

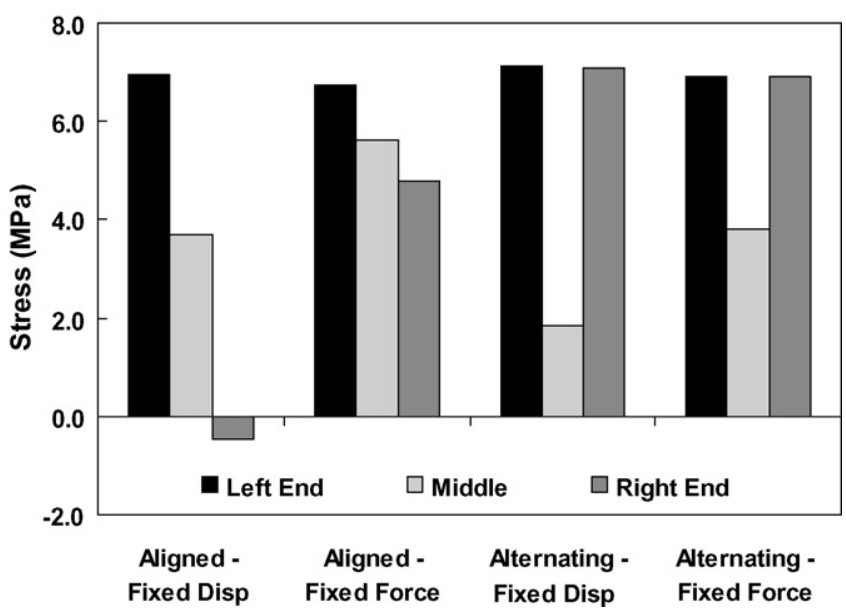

Fig. 11. Maximum in-plane residual stresses obtained at the three points of the membrane; the left end, the midpoint and the right end, shown for each alignment and clamping method.

(iii) For all cases, the shear stresses are small, with the alternating case causing the higher shear stresses in the membrane. The maximum shear stresses are at the midpoint of the membrane for all cases (Fig. 7).

The residual, in-plane stresses found after unloading are plotted at the three points (Left, Middle, Right) of the membrane which correspond the maximum and the minimum values of the stresses. As seen from Fig. 11, the residual in-plane stresses are tensile, except for the right end of the membrane in the alignedfixed displacement case since no plastic deformation occurs, as discussed in Section 5.2. Also, for all cases the maximum residual stresses are similar.

\section{Conclusions}

The mechanical response of a PEM subjected to a single hygro-thermal loading cycle, simulating a simplified single fuel cell duty cycle, was investigated. A linear, uncoupled temperature and humidity profile, assuming steady-state conditions, was used for the loading-unloading. Linear-elastic, perfectly plastic material response with temperature and humidity dependent material properties was used to study the plastic deformation behavior of the membrane during the cycle. Independent of the clamping method and alignment, plastic deformation always occurs. However, the residual stresses in the membrane directly correlate with alignment and clamping method.

For "fixed displacement," stresses are generally higher than those assuming "fixed force." The shear stresses are small for all cases, although alternating gas channel alignment produces higher shear stresses (less than 15\% of the in-plane stress at maximum). The out-of-plane stress is small compared to the in-plane stress, especially for the fixed displacement case. In general, the in-plane stress is the largest stress component during the loading sequence, thus it controls the yielding behavior.

Hygro-thermal loading causes compressive stresses in the membrane due to the constraints, which prevent expansion due to the swelling of the membrane. During unloading, the membrane 
shrinks and due to redistribution of the stresses caused by the plastic deformation, tensile residual stresses may develop during cooling/drying. In many cases, the residual stresses become large enough to cause tensile yielding. We believe that these high in-plane residual stresses are a significant contributor to the mechanical failures observed in the membranes since they may cause the propagation of through-the-thickness flaws or tearing in the membrane.

In conclusion, we have shown that use of temperature and humidity dependent material properties in the mechanical modeling of the membranes leads to critical residual stresses after one fuel cell duty cycle. The results suggest that the in-plane residual tensile stresses developed upon unloading, may lead to the failure of the membranes due to the mechanical fatigue. Therefore, in order to acquire a complete understanding of these damage mechanisms in the membranes, mechanical response under continuous hygro-thermal cycles should be studied under realistic cell operating conditions.

\section{Acknowledgements}

This research has been supported by W.L. Gore \& Associates, Inc. and the State of Delaware through the Clean Energy Partnership.

\section{References}

[1] U. Beuscher, S.J.C. Cleghorn, W.B. Johnson, Int. J. Energy Res. 29 (2005) $1103-1112$.

[2] J. Xie, D.L. Wood, D.M. Wayne, T.A. Zawodzinski, P. Atanassov, R.L. Borup, J. Electrochem. Soc. 152 (2005) A104-A113.

[3] W. Liu, K. Ruth, G. Rusch, J. New Mat. Elect. Syst. 4 (2001) 227-231.

[4] S. Cleghorn, J. Kolde, W. Liu, Catalyst coated composites membranes, in: W. Vielstich, H.A. Gasteiger, A. Lamm (Eds.), Handbook of Fuel Cells-Fundamentals, Technology and Applications, John Wiley \& Sons Ltd., 2003.

[5] P. Gode, J. Ihonen, A. Strandroth, H. Ericson, G. Lindbergh, M. Paronen, F. Sundholm, G. Sundholm, N. Walsby, Membrane durability in a PEM fuel cell studied using PVDF based radiation grafted membranes, Fuel Cells 3 (1/2) (2003) 21-27.

[6] Y. Lai, C.K. Mittelsteadt, C.S. Gittleman, D.A. Dillard, Viscoelastic stress model and mechanical characterization of perfluorosulfonic acid (PFSA) polymer electrolyte membranes, in: Proceedings of the Third International Conference on Fuel Cell Science, Engineering and Technology, Ypsilanti, Michigan, May 23-25, 2005, pp. 161167.

[7] V. Stanic, M. Hoberecht, Mechanism of pin-hole formation in membrane electrode assemblies for PEM fuel cells, in: Proceedings of the Fourth International Symposium on Proton Conducting Membrane Fuel Cells, 2004.

[8] R.G. Rajendran, Polymer electrolyte membrane technology for fuel cells, MRS Bull. 30 (8) (2005) 587-590.

[9] Y. Lai, M. Budinski, C.S. Gittleman, D.A. Dillard, Tear resistance of proton exchange membranes, in: Proceedings of the Third International Conference on Fuel Cell Science, Engineering and Technology, Ypsilanti, Michigan, May 23-25, 2005, pp. 153-159.

[10] A. Webber, J. Newman, AIChE J. 50 (2004) 3215-3226.

[11] J.T. Uan-Zo-li, The effects of structure, humidity and aging on the mechanical properties of polymeric ionomers for fuel cell applications, Master Thesis, Virginia Tech., 2001.

[12] V. Mehta, J.S. Cooper, J. Power Sources 114 (2003) 32-53.

[13] Y. Tang, M.H. Santare, A.M. Karlsson, S. Cleghorn, W.B. Johnson, Stresses in proton exchange membranes due to hydration and dehydration cycles, in: Proceedings of the Third International Conference on Fuel Cell Science, Engineering and Technology, Ypsilanti, Michigan, May 23-25, 2005, pp. 207-213.

[14] Y. Tang, M.H. Santare, A.M. Karlsson, S. Cleghorn, W.B. Johnson, Stresses in proton exchange membranes due to hydro-thermal loading, J. Fuel Cell Sci. Technol. 3 (2006) 119-124.

[15] Y. Tang, A.M. Karlsson, M.H. Santare, M. Gilbert, S. Cleghorn, W.B. Johnson, An experimental investigation of humidity and temperature effects on the mechanical properties of perfluorosulfonic acid membrane, J. Mater. Sci. 425 (2006) 297-304.

[16] R. Hill, The Mathematical Theory of Plasticity, Clarendon Press, Oxford, 1950.

[17] Product Information, Toray Industries, Inc.

[18] Product Information, DuPont Nafion PFSA Membranes N-112, NE1135, N-115, N-117, NE-1110 Perfluorosulfonic Acid Polymer, NAE101, 2004.

[19] ABAQUS Analysis User's Manual, Hibbitt, Karlsson \& Sorensen, Inc., 2003. 